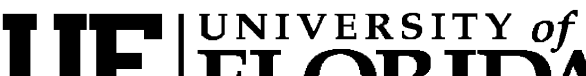 FLORIDA \\ IFAS Extension
}

SS AGR 272

\section{Benefits of Cover Crops for Soil Health ${ }^{1}$}

\author{
Y.C. Newman, D.W. Wright, C. Mackowiak, J.M.S. Scholberg and C.M. Cherr ${ }^{2}$
}

\section{Introduction}

Cover crops shield the soil from sunlight, wind, and heavy rainfall thus improving soil structure, water infiltration, and root penetration. Additional benefits include reduced soil crusting, soil erosion, run-off, and nutrient leaching. Cover crops enhance soil fertility via improved nutrient retention and cycling while leguminous cover crops add nitrogen from the atmosphere. A cover crop is termed a green manure crop if the residue is incorporated in the soil; in such instances, crops should be selected that produce large quantities of herbage and also contain adequate amounts of nutrients in the correct proportions. Cover crops are often used for strip tillage by row crop farmers to gain the benefits of surface residues.

From the standpoint of supplying plant nutrients in a readily available form, commercial chemical fertilizers are relatively cheap and concentrated.

Nutrient content and release rates tend to be predictable and fast (except for "slow release" fertilizers). Most organic amendments are "bulky" and transportation/application costs may be expensive and cost or time prohibitive. Cover crops, on the other hand, may provide an affordable on-site management option to enhance inherent soil fertility and soil organic matter. Although chemical fertilizer materials are easy to store, apply, and manage, they do not add to soil organic matter except through adding enhanced plant residues over a period of time.

\section{Benefits of Soil Organic Matter}

Increasing soil organic matter enhances the capacity of the soil to store nutrients and water. Almost all of the nitrogen and much of soil phosphorus and sulfur resides in the soil organic matter. Soil organic matter increases the soil cation exchange capacity therefore enhancing the capacity of soil to hold macronutrients such as potassium, calcium and magnesium. Micronutrients, such as iron, zinc, copper, manganese, and molybdenum, form complexes with organic matter, which increases their availability for plant uptake, as well. Organic matter provides carbon as energy for microorganisms that help make many

1. This document is SS AGR 272, one of a series of the Agronomy Department, Florida Cooperative Extension Service, Institute of Food and Agricultural Sciences, University of Florida. Original publication date November 2007. Visit the EDIS Web Site at http://edis.ifas.ufl.edu.

2. Y.C. Newman, assistant professor, Forage Extension Specialist, Agronomy Department; D.W. Wright, professor, Agronomy Department; C. L. Mackowiak, assistant professor, Soil and Water Science Department, North Florida Research and Education Center--Quincy, FL; J.M.S. Scholberg [will be added later]; and C.M. Cherr

The use of trade names in this publication is solely for the purpose of providing specific information. UF/IFAS does not guarantee or warranty the products named, and references to them in this publication does not signify our approval to the exclusion of other products of suitable composition.

The Institute of Food and Agricultural Sciences (IFAS) is an Equal Opportunity Institution authorized to provide research, educational information and other services only to individuals and institutions that function with non-discrimination with respect to race, creed, color, religion, age, disability, sex, sexual orientation, marital status, national origin, political opinions or affiliations. U.S. Department of Agriculture, Cooperative Extension Service, University of Florida, IFAS, Florida A. \& M. University Cooperative Extension Program, and Boards of County Commissioners Cooperating. Larry Arrington, Dean 
soil nutrients more available through

mineralization processes. The high

buffering capacity of soil organic matter

lessens the stress in the plant caused by

improper fertilization. Organic matter

increases soil water holding capacity in

sandy soils and improves water percolation

in heavy, clay soils. Physical properties of

the soil are also affected; soil organic matter

stabilizes soil structure, thereby improving

soil tilth.

Residues that are more woody or coarse and have low nitrogen content tend to decompose slowly and may be less effective in protecting the soil. Perennial pastures, on the other hand, are superior in building up and protecting the soil and the residues decompose slowly which results in organic matter increases over time. Although annual crops may also generate a lot of biomass, frequent tillage may partially off-set soil organic matter gains associated with the addition of plant material to the soil.

Some legumes, like sunnhemp, sesbania, aeschynomene, and hairy indigo, produce very fibrous or woody stems if grown to full maturity. Woody stems are not considered a serious problem for agronomic crops since they are quite brittle and can be easily shredded with a tractor-powered rotary mower. However, at times these stems may interfere with bed formation in commercial horticultural crop fields and it is important to mow the crop before stems become overly woody. Also, the residue tends to decompose more slowly and may initially tie up (immobilize) nutrients longer, thereby temporarily hampering nutrient availability for subsequent commercial crops

\section{Matching cover crop nutrient release with future crop demand}

Since nutrient release from organic materials is controlled by biological processes and climatic conditions, it is less predictable compared to chemical fertilizers. First, it is difficult to determine how much cover crop will be produced and its corresponding nutrient content. Second, it is difficult to determine how fast this material is going to decompose (mineralize) in the soil.

However, some basic guidelines may help

to streamline the process of matching nutrient release from cover crops with the nutrient demand of subsequent commercial crops.

The amount of herbage (biomass) produced by a cover crop depends on the plant species, the fertility level under which it is grown, the amount of rain and residual soil moisture, the length of its growing season, the soil type, and possibly several other factors. It is important to keep in mind that most of the nitrogen benefit from green manuring of a legume crop is only obtained if the crop is turned under at the stage of $50 \%$ flowering or before it produces seed. Likewise, legume cover crop residue that is killed and incorporated into the soil decomposes rapidly and most of the nitrogen is released in the first 30 days. This does not correspond with the nutrient needs of most subsequent crops in many cases. Grasses and grains usually produce more biomass than legumes under adequate fertility levels. Since grass herbage is usually lower in nitrogen content than legumes, it decomposes more slowly. Crops planted soon after large amounts of grass herbage have been incorporated into the soil may require additional nitrogen fertilizer to prevent nitrogen immobilization, which robs the subsequent crop of needed nitrogen.

Mixing a grain crop with a leguminous crop (e.g. $30 \%$ hairy vetch-70\% winter rye mix) may prove beneficial provided the crops complement each other in terms of growth and nutrient capture (e.g. nutrient mining vs. nitrogen fixation). In the case of the above mix, the residue of the mix decomposes faster than pure rye, thus reducing the risk of nitrogen immobilization.

\section{Timing and Depth of Residue Incorporation}

In North Florida, use of a summer cover crop such as sunnhemp may not benefit a spring crop like sweet corn since most of the $\mathrm{N}$ may be lost due to leaching between the time the sunhemp is finished and the corn crop is planted. In this case, nitrogen benefits are relatively small $(<30 \%)$. In placeSouth Florida, 
on the other hand, sunnhemp can be directly followed by a commercial fall vegetable crop. In this case the nitrogen from the crop residues can be used much more efficiently and $\mathrm{N}$-fertilizer rates may be reduced by $50-75 \%$. In some cases, the time of optimal biomass production of the winter cover crop (mid-April) may be later than the optimal time of planting the summer crop. Some crops like crimson clover may die naturally as the spring proceeds and intercropping may be an option. Other crops, like hairy vetch, may be rather aggressive and might require herbicide application and/or mowing prior to planting to prevent potential competition. As discussed above, cover crops with a tendency for "weediness" should be mowed in a timely fashion ("prevention is the best cure").

Use of minimum or conservation tillage tends to slow residue decay and promotes the build up of a residue layer on top of the soil. Although minimum tillage may reduce soil organic matter losses, it may also interfere with planting and require the use of special equipment.

Although a grain crop like winter rye does not add supplemental $\mathrm{N}$ to the soil, it can be more efficient in mining other nutrients from deeper soil layers and thus may improve poorer soils. Fast growing and deep root systems enhance a plant's ability to mine/recover scarce soil nutrients while deep rooted plants may also increase soil organic matter at greater depths. Pearlmillet, sorghum-sudan hybrids, and pangola digitgrass usually develop deeper root systems than cool season grasses while bahiagrass also tends to mine lower soil layers (the spodic) horizon for nutrients including phosphorus. The depth to water table and the distribution of plant nutrients throughout the soil profile will influence this activity. The greatest root activity and growth will be in areas of optimum soil moisture, soil air, and plant nutrient concentrations.

\section{Erosion, pest, and weed control}

Cover crops shade the soil (which reduces weed germination) and they also compete with weeds for light, water, and nutrients. Where weed control is important, a cover crop should germinate quickly and develop a rapidly growing and dense herbage that can effectively "shade out" weeds. Some crops, such as winter rye and sunnhemp, also produce natural herbicides (alellopathic substances) that hamper weed germination. For erosion control, a cover crop should establish quickly, and form both a solid groundcover and an extensive root system.

One of the issues of concern with cover crops is the potential they have to become pests. This is particularly a risk if they are permitted to produce seed, which could germinate and create a weed problem in subsequent crops. With iron clay cowpea this may be a problem in vegetable systems unless it is mowed before it sets seed. For the millets and sorghum-sudan hybrids, this may involve one or more mowings during the summer. Whether mowing is required will depend on how long the cover crop is allowed to grow, the maturity rating of the variety being used, and the subsequent commercial crop that is planned. Some varieties of sorghum or sorghum-sudan that are very late maturing may not flower before they are removed or destroyed. It may also be possible to purchase seed of a variety that is sterile and/or will not produce seed as is the case for sunnhemp. Some varieties of pearl millet and sorghum-sudan grasses will produce seed heads 6-8 weeks after planting. If these seed heads are mowed off, new ones will be produced in about a month. With a March planting, four to five mowings will be required to entirely prevent seed formation before the cover crop is destroyed in August or September

Most of the legumes do not produce an abundance of seed until late in the growing season, so the risk of germination is not as severe. With the exception of cowpea, hairy indigo, and annual ryegrass, most cover crops are not a problem for the succeeding crop. The legumes mentioned require 60 (cowpea) to 100 days (hairy indigo) to produce viable seed. Practically all of them will produce seed in the early fall months whether they are mowed or not. Sometimes seed develop on stems growing more 
prostate along the ground. Vegetable growers using the full-bed plastic mulch system, as well as other growers, should guard against planting certain legumes that have a high percentage of hard seed such as alyceclover, hairy indigo or white clover. The hard seed of these legumes will lie dormant in the soil for months or even years and then germinate when the vegetable crop is planted. Hairy indigo has become a major weed pest in many fields after being grown as a cover crop.

Winter rye, sunnhemp, velvet bean and hairy indigo may reduce nematode populations. Clovers, lupine, sesbania and vetch tend to be nematode hosts. Since there are many types of pests that require different hosts, a cover crop should be selected that is a non-host plant for problems like pests insects, diseases, and nematodes that attack the cash crop (e.g. nematodes affecting alyceclover do not attack citrus trees). As a general rule, use a grass cover crop prior to growing a broadleaf cash crop, and use a broadleaf cover crop prior to growing a grass crop such as corn.

Cover crops are beneficial for improving soil quality and fertility for the succeeding cash crop. They can be used for grazing, hay or seed production as well as provide environmental benefits by minimizing soil and water erosion and nutrient losses.

\section{Further Reading:}

Cherr, C.M., J.M.S. Scholberg, and R. McSorley. 2006. Green manure approaches to crop production: a synthesis. Agronomy Journal 98:302-319.

Y. Li, E. A. Hanlon, W. Klassen, Q. Wang, T. Olczyk, and I. V. Ezenwa. 2006. Cover crop benefits for South Florida commercial vegetable producers. EDIS publication SL242. http://edis.ifas.ufl.edu/pdffiles/SS/SS46100.pdf 